\title{
Telephone triage of cardiac emergency calls by dispatchers: a prospective study of 1386 emergency calls
}

\author{
Michael Srámek, Wilfried Post, Rudolph W Koster
}

\begin{abstract}
Objectives-To evaluate the handling of potential cardiac emergency calls by dispatchers, to determine their final diagnosis and urgency, and to determine the value of the main complaint in predicting urgency and the ability of the dispatchers to recognise non-urgent conditions.

Design-Prospective data collection and recording of main complaint of emergency calls placed via the 06-11 alarm telephone number with follow up to hospital when the patients were transported and the general practitioner when they were not.
\end{abstract}

Setting-Dispatch centres of the emergency medical services in Amsterdam (urban area) and Enschede (rural area).

Patients-1386 consecutive adult subjects of emergency calls placed by citizens about chest problems or unconsciousness not caused by injury.

Main outcome measures-Frequency of characteristics of the calls, outcome in diagnosis, and assessment of urgency. Results-69 (5\%) patients were dead when the ambulance arrived. Diagnosis was established in 1071 patients (77\%). The disorders most often reported were cardiac, with acute ischaemia in $15 \%$ of all subjects. In $28 \%$ of cases and for each presenting complaint no organic explanation was found. Overall $39 \%$ of all emergency calls were urgent; the urgency rate was lowest for calls for people with abdominal discomfort. Dispatchers correctly identified $90 \%$ of the non-urgent calls, but $55 \%$ of the calls that they identified as urgent proved to be non-urgent. Conclusion-Currently, direct dialling for an ambulance without the intervention of a general practitioner imposes a high work load on emergency systems and hospitals because triage by dispatchers is not sufficiently accurate. It may be possible to increase the accuracy of triage by developing and testing decision algorithms.

(Br Heart f 1994;71:440-445)

In The Netherlands the role of general physicians includes triage and management of acute medical conditions. In 1990 a nationwide emergency telephone number, 06-11, was introduced and the public was instructed to dial $06-11$ in urgent conditions. Because the new service provided an ambulance without the intervention of a general practitioner it reduced the delay in obtaining help for people with acute conditions, such as acute myocardial infarction. ${ }^{12}$ General practitioners claim that the introduction of 06-11 led to many ambulances being dispatched unnecessarily because dispatchers work on the principle of safety first.

We evaluated the way emergency calls were handled by dispatchers and how decisions were taken by ambulance staff in a large city (Amsterdam) and a medium sized city with a large rural population (Enschede). We determined the final diagnoses from the hospital or general practitioner and established the true urgency of the calls. We also evaluated the additional option in Enschede of sending an on call general practitioner instead of an ambulance.

\section{Patients and methods}

SETTING

We studied the emergency medical systems of Amsterdam (1 200000 inhabitants) and Enschede (260 000 inhabitants). Both services use nurse-dispatchers. Also 06-11 calls are answered on lines dedicated to doctors and public services (such as the police, fire department and public transport).

In The Netherlands 06-11 medical emergency calls are dealt with by dispatchers in 40 emergency medical services. Most dispatch centres use nurses, who are often experienced with ambulances, but not specifically trained in dispatching. Formal protocols are not used. In nearly all emergency medical services dispatchers have two options: to dispatch an emergency ambulance or to refer the patient to their general practitioner. An exception is the Enschede emergency medical services, in which dispatchers have the additional option of contacting the on duty general practitioner to order an immediate visit.

All ambulances in Amsterdam and Enschede are equipped to the same level and staffed by a driver with basic training in first aid and a nurse with training in general and psychiatric nursing and licensed to perform defibrillation, provide intravenous drugs, and perform endotracheal intubation according to protocols. They can transport the patient to a hospital or help the patient without taking them to hospital. Ambulance staff often consult the patient's general practitioner while they are attending the patient. 
DESIGN

Because we wanted to examine 06-11 calls where acute cardiac problems were a possibility we used the following four criteria for entry into this study: ( $a$ ) calls had to be placed by citizens dialling 06-11 and not by healthcare professionals; $(b)$ only patients over 16 years of age were considered; $(c)$ the problem had to be medical but not related to injury; and $(d)$ the complaint had to include impaired consciousness or symptoms attacking the body area between the jaws and the upper abdomen, including the arms.

The dispatchers entered details of the age, sex, and the chief complaint of the patient on computer. Then they entered their decision: ambulance dispatch or referral to the patient's general practitioner. In Enschede the decision to instruct a general practitioner to make an immediate visit was also recorded.

\section{FOLLOW UP}

When a patient was referred to his or her general practitioner (ambulance not dispatched) or when an ambulance was dispatched but the patient was not taken to hospital a questionnaire was sent to the patient within 4 days; the questionnaire was sent two more times to non-responders. ${ }^{3}$ It asked what had happened to the patient since the emergency call, whether the patient had consulted the general practitioner or attended a hospital and what had been diagnosed. Furthermore, the patient was asked to provide the general practitioner's name and telephone number for more detailed information. When the duty doctor had visited he or she was contacted by telephone within 4 days to establish a diagnosis and possible secondary referral to hospital. When a patient was taken to hospital, the hospital was contacted by telephone. If a patient had not been admitted the diagnosis on discharge from the emergency room was recorded and if he or she had been admitted the diagnosis on discharge was recorded.

Diagnoses were coded in 43 categories. Unstable angina was coded only when an acute myocardial infarction had to be excluded by serum enzyme measurements in a patient in whom acute myocardial infarction was suspected.

\section{ASSESSMENT OF URGENCY}

All information was reviewed independently by a cardiologist and a general physician. The urgency of the condition was established by the final diagnosis and treatment of each patient. An urgent condition was defined as a call for a condition for which immediate treatment was needed and in which the medical condition made it undesirable to add the delay of having a general practitioner evaluate the patient's condition first (a delay expected to range between 15 minutes and 2 hours). The location of the patient at the time of the emergency call was accounted for: a condition arising outside the patient's residence precludes a visit by a general practitioner first, but this does not necessarily define the condition as urgent. Calls in which the patient was dead when the ambulance arrived were classified as urgent, although it was not possible to determine the cause and moment of death. When the classification was conflicting the case was reviewed by both reviewers simultaneously until consensus was achieved. The dispatcher defined as urgent calls that resulted in an ambulance being dispatched. Calls resulting in referral to the general practitioner were defined as non-urgent.

\section{ANALYSIS OF CALLS}

During the first two months of the study 06-11 calls were also recorded on tape. If the call did not meet the entry criteria according to the dispatcher the tape was stopped; otherwise the call was recorded completely. All recorded calls were analysed for the correct recognition of the entry criteria. Entirely recorded calls (fulfilling the entry criteria according to the dispatcher) were further analysed according to $(a)$ the identity of the caller; $(b)$ the degree of panic in the caller's voice $^{4} ;(c)$ the person taking the lead in the call; and $(d)$ the duration of the call. The panic was defined as a score of 3 or 4 on a 1-4 scale, 1 being calm, 2 being normal conversational speech, 3 being emotional with difficulty in providing adequate information and 4 being so distraught that information could not be obtained.

Four types of callers were identified: a messenger (person who had been asked to dial 06-11 without having seen the patient), a witness (person who had seen the patient but was not familiar with the patient's background), a relative or friend (located in the patient's direct vicinity), and the patient.

\section{STATISTICS}

Frequency distributions were used in determining the distribution of diagnoses and call characteristics and in the assessment of urgency. $\chi^{2}$ Statistics were used to determine differences in distribution of diagnoses and urgency, in relation to the characteristics of the decision and call. ${ }^{5}$ We used the KruskalWallis test to determine differences in the duration of the calls between the groups of callers and the Mann-Whitney U test to compare two groups. Student's $t$ test was used for analysis of continuous variables. Results were considered significant when $\mathrm{p}<0.05$.

\section{Results}

HANDLING OF CALLS

During the first two months of the study 1100 calls were recorded on tape and were analysed to assess the way the dispatchers handled the entry criteria for the study (table 1 ). In $94 \%$ of the calls the entry criteria were used correctly by the dispatcher. In the remaining $6 \%$ the dispatcher almost always decided incorrectly to exclude the call from the study. Only six calls (1.5\% of all included calls) were wrongly included.

During the whole study, July 1991 until April 1992, there were 1386 emergency 
Table 1 Handling of entry criteria in 1100 calls

\begin{tabular}{|c|c|c|c|c|c|c|}
\hline \multirow{3}{*}{$\begin{array}{l}\text { Meeting criteria } \\
\text { according to } \\
\text { dispatcher }\end{array}$} & \multicolumn{6}{|c|}{ Meeting criteria after review } \\
\hline & \multicolumn{3}{|c|}{ in Amsterdam } & \multicolumn{3}{|c|}{ in Enschede } \\
\hline & Yes & No & Total & Yes & No & Total \\
\hline $\begin{array}{l}\text { Yes } \\
\text { No } \\
\text { Total }\end{array}$ & $\begin{array}{r}322 \\
55 \\
377\end{array}$ & $\begin{array}{r}5 \\
518 \\
523\end{array}$ & $\begin{array}{l}327 \\
573 \\
900\end{array}$ & $\begin{array}{r}72 \\
8 \\
80\end{array}$ & $\begin{array}{r}1 \\
119 \\
120\end{array}$ & $\begin{array}{r}73 \\
127 \\
200\end{array}$ \\
\hline
\end{tabular}

Table 2 Outcome of 1386 emergency calls. Values are numbers (percentages) of calls

\begin{tabular}{lcc}
\hline & $\begin{array}{c}\text { Amsterdam } \\
(n=1171)\end{array}$ & $\begin{array}{l}\text { Enschede } \\
(n=215)\end{array}$ \\
\hline $\begin{array}{l}\text { Ambulance: } \\
\quad \begin{array}{l}\text { Not dispatched } \\
\text { Dispatched but did not } \\
\text { transport patient }\end{array}\end{array}$ & $93(8)$ & $17(8)$ \\
$\begin{array}{c}\text { Dispatched and } \\
\text { transported patient }\end{array}$ & $345(29)$ & $46(21)$ \\
$\begin{array}{c}\text { House call assigned } \\
\text { How }\end{array}$ & 0 & $110(51)$ \\
\hline
\end{tabular}

calls fulfilling the entry-criteria (1171 in Amsterdam and 215 in Enschede). Table 2 summarizes the handling of these calls by both emergency medical services. The proportion of non-dispatching and non-transportation calls was the same, but many patients in Enschede were visited by the emergency general practitioner when an ambulance would have been dispatched in Amsterdam. Seven of these 42 visits resulted in an emergency admission on the request of the visiting general practitioner.

\section{FOLLOW UP}

Of the 110 patients referred to a general practitioner in Amsterdam and Enschede, 98 patients were sent a questionnaire, of which 60 were returned. The correct name or address of the 12 remaining patients was unknown.

Of the 391 patients who were not transported to hospital, 69 ( $5 \%$ of the total) were dead when the ambulance arrived and in 33 the name or address was unknown. The questionnaire was returned by 187 of the 289 patients to whom it was sent.

Of the 42 patients who received a visit, two patients proved untraceable. The general practitioner's diagnosis was obtained for the 40 others. Of the 843 patients taken to hospital, $47(6 \%)$ were untraceable, and 12 patients were transported to hospitals outside the area covered by both emergency medical services; the diagnosis on discharge from the emergency room was obtained for 784 patients. There were no significant differences in the response rates of patients in either city.

No diagnosis could be established for the patients who were dead on arrival $(4 \%$ in Amsterdam and $8 \%$ in Enschede, $p=0.02$ ). There was no significant difference in the median time taken for the ambulance to arrive (time between dispatching the ambulance and its arrival at the patient) in this group compared with the group of patients who were alive, $(5.2$ minutes $v 5.8$ minutes).

Follow up was completed and diagnoses
Table 3 Distribution of diagnoses in 1071 patients

\begin{tabular}{|c|c|}
\hline Diagnosis & No of patients \\
\hline \multicolumn{2}{|l|}{ Cardiology $(n=369)$} \\
\hline \multicolumn{2}{|l|}{ Angina } \\
\hline Unstable & 56 \\
\hline Stable & 49 \\
\hline Possible & 17 \\
\hline Atrial fibrillation/flutter & 22 \\
\hline Re-entry tachycardia & 1 \\
\hline Heartblock & 2 \\
\hline Ventricular fibrillation/tachycardia & 32 \\
\hline Other arrhythmia & 15 \\
\hline Heart failure & 11 \\
\hline Cardiac asthma & 40 \\
\hline Other & 16 \\
\hline \multicolumn{2}{|l|}{ Pulmonary $(n=57)$} \\
\hline Bronchial asthma & 35 \\
\hline Status asthmaticus & 0 \\
\hline Pulmonary embolism & 4 \\
\hline Pneumothorax & 1 \\
\hline Tension pneumothorax & 0 \\
\hline Pneumonia & 9 \\
\hline Other & 8 \\
\hline \multicolumn{2}{|l|}{ Gastroenterology $(n=58)$} \\
\hline Acute abdomen & 8 \\
\hline Biliary/renal colic & 12 \\
\hline Peptic ulcer & 1 \\
\hline Gastric perforation & 6 \\
\hline Other & 31 \\
\hline \multicolumn{2}{|l|}{$\begin{array}{l}\text { Trauma }(n=30) \\
\text { Distortion/luxation }\end{array}$} \\
\hline Distortion/luxation & 5 \\
\hline Fracture & 11 \\
\hline Multiple trauma & 2 \\
\hline Other & 12 \\
\hline \multicolumn{2}{|l|}{ Obstetrics and gynaecology $(n=7)$} \\
\hline Ectopic pregnancy & 1 \\
\hline Other obstetrics & 3 \\
\hline Other gynaecology & 3 \\
\hline \multicolumn{2}{|l|}{$\begin{array}{l}\text { Internal disorder }(n=94) \\
\text { Hypotension }\end{array}$} \\
\hline Hypotension & 27 \\
\hline Hypoglycaemia & 22 \\
\hline Other disorder & 45 \\
\hline \multicolumn{2}{|l|}{ Neurology $(n=121)$} \\
\hline Epilepsy & 53 \\
\hline Status epilepticus & 1 \\
\hline Stroke & 32 \\
\hline Other & 35 \\
\hline Intoxication & 29 \\
\hline Psychiatric & 10 \\
\hline \multicolumn{2}{|l|}{$\begin{array}{l}\text { Non-organic disorder }(n=296) \\
\text { No cause found }\end{array}$} \\
\hline No cause found & 134 \\
\hline Hyperventilation syndrome & 78 \\
\hline Non-organic chest pain & 84 \\
\hline
\end{tabular}

were obtained in 907 patients in Amsterdam $(77 \%)$ and 164 patients in Enschede (76\%). Urgency was thus determined in 1140 patients.

DIAGNOSES AFTER FOLLOW UP

Apart from a difference in the prevalence of neurological diseases (due to a significantly higher prevalence of epilepsy in Enschede, $10 \%(17 / 164) v 4 \%(36 / 907), \mathrm{p}=0.003)$, no significant differences were found in the distribution of diagnoses. Therefore, analysis was performed on the combined distribution of diagnoses (table 3). Thirty four per cent of all calls proved to be about a cardiac condition. Acute ischaemia (acute myocardial infarction and unstable angina) was the final diagnosis in $15 \%$ of all cases. Arrhythmias other than ventricular fibrillation and ventricular tachycardia, such as atrial fibrillation, were not often encountered, probably because these arrhythmias had resulted in heart failure or angina.

In Table 4, the distribution of diagnoses is presented in relation to the complaints. The most commonly encountered complaints were impaired consciousness and chest discomfort, which together accounted for $76 \%$ of all calls. 
Table 4 Distribution of diagnoses in relation to complaints. Values are percentages

\begin{tabular}{|c|c|c|c|c|c|}
\hline \multirow[b]{2}{*}{ Diagnosis after follow up } & \multicolumn{5}{|c|}{ Main complaint(s) at time of emergency call } \\
\hline & $\begin{array}{l}\text { Impaired } \\
\text { consciousness } \\
\text { only } \\
n=400\end{array}$ & $\begin{array}{l}\text { Dyspnoea } \\
\text { only } \\
n=105\end{array}$ & $\begin{array}{l}\text { Chest discomfort } \\
\text { only } \\
n=315\end{array}$ & $\begin{array}{l}\text { Abdominal pain } \\
\text { only } \\
n=55\end{array}$ & $\begin{array}{l}\text { With chest } \\
\text { discomfort } \\
n=411\end{array}$ \\
\hline Cardiology: & 17 & 34 & 63 & 2 & 58 \\
\hline Acute ischaemia & 4 & 10 & 35 & - & 31 \\
\hline Stable angina & i & 2 & 15 & - & 13 \\
\hline Ventricular fibrillation/tachycardia & 6 & - & 1 & - & 1 \\
\hline Other arrhythmia & 4 & 4 & 5 & - & 5 \\
\hline Heart failure & 1 & 16 & 6 & - & 7 \\
\hline Other & 1 & 2 & 1 & 2 & 1 \\
\hline Pulmonary & 3 & 27 & 3 & 2 & 4 \\
\hline Gastroenterological & 2 & 1 & 2 & 58 & 2 \\
\hline Obstetric and gynaecological & 1 & - & - & 5 & - \\
\hline Other internal disorder & 15 & 7 & 3 & 9 & 3 \\
\hline Neurology & 22 & 6 & 2 & - & 3 \\
\hline Intoxication & 6 & 1 & 1 & - & 1 \\
\hline Injury & 4 & $i$ & - & - & - \\
\hline Psychiatric & 1 & 1 & 1 & - & 1 \\
\hline Non-organic disorder: & 29 & 22 & 25 & 24 & 27 \\
\hline No cause found & 23 & 10 & - & 20 & - \\
\hline Hyperventilation & 6 & 11 & 7 & 2 & 8 \\
\hline Non-organic chest pain & - & 1 & 18 & 2 & 19 \\
\hline
\end{tabular}

Table 5 Distribution of main complaints in relation to true urgency assessment after follow up in 1140 patients (1071 received diagnosis and 69 were dead on arrival)

\begin{tabular}{lcc}
\hline Complaint & No of patients with complaint & No (\%) urgent \\
\hline Unconsciousness only & 453 & $181(40)$ \\
Dyspnoea only & 48 & $21(44)$ \\
Chest discomfort only & 322 & $138(43)$ \\
Abdominal discomfort only & 55 & $8(14)^{\star}$ \\
Unknown complaint & 79 & $22(28) \dagger$ \\
Combination of complaints & 123 & $41(33)$ \\
Any combination which included & 418 & $176(42)$ \\
chest discomfort & 1140 & $445(39)$ \\
\hline
\end{tabular}

${ }^{{ } \mathrm{p}<0.005}$ and $\mathrm{tp}=0.03$, compared with all complaints.

Of the 164 calls related to acute ischaemia, $111(68 \%)$, had mentioned chest pain as the only complaint. In $11(7 \%)$ dyspnoea was the only presenting complaint, and in $17(10 \%)$ acute ischaemia was manifested as impaired consciousness. In $19(12 \%)$ a combination of complaints was reported and in the remaining $3 \%$ the complaint was unknown. In 127 $(77 \%)$ chest pain was reported.

The finding of no organic cause for the symptoms was equally distributed over all presenting complaints, including impaired consciousness.

MAIN COMPLAINTS AND URGENCY

There was no significant difference in the overall urgency rate of all calls between Enschede and Amsterdam, or any significant differences in urgency rate in relation to the main complaint between both emergency medical services. Therefore, the analysis of urgency at follow up was performed for both cities together. Table 5 shows the distribution of calls in relation to the main complaint and the assessment of true urgency at follow up. Calls dealing with abdominal discomfort only and those dealing with an unknown complaint, had a significantly lower urgency rate compared with the others.

\section{CALLER AND URGENCY}

Table 6 shows the main complaints in relation to the caller and the true urgency rate, as determined in 398 of the 400 taped calls during the first two months of the study. Fifty one percent of calls were placed either by a messenger or a witness $(44 \%$ and $7 \%$ respectively). Ten percent of calls were placed by the patient and the remaining $39 \%$ by a relative or friend in the patient's direct vicinity.

Both messengers and witnesses predominantly reported impaired consciousness as the main problem; patients themselves most frequently called for complaints affecting the chest.

Overall, calls placed by relatives had a significantly higher urgency rate than calls placed by others $(p<0.01)$. This difference applied to either impaired consciousness or dyspnoea as the only complaint or in combination with other complaints $(47 \% v 27 \%$, respectively $75 \% v 18 \%$ and $47 \%$ v $18 \%$, all $\mathrm{p}<0.05)$.

Table 6 Distribution of complaints in 398 calls in relation to caller

\begin{tabular}{|c|c|c|c|c|c|c|c|c|}
\hline \multirow[b]{2}{*}{ Complaints } & \multicolumn{2}{|l|}{ Messenger } & \multicolumn{2}{|l|}{ Witness } & \multicolumn{2}{|l|}{ Patient } & \multicolumn{2}{|l|}{ Relative } \\
\hline & $\begin{array}{l}\text { No of } \\
\text { patients with } \\
\text { complaints }\end{array}$ & $\begin{array}{l}\text { No (\%) } \\
\text { urgent }\end{array}$ & $\begin{array}{l}\text { No of } \\
\text { patients with } \\
\text { complaints }\end{array}$ & $\begin{array}{l}\text { No (\%) } \\
\text { urgent }\end{array}$ & $\begin{array}{l}\text { No of } \\
\text { patients with } \\
\text { complaints }\end{array}$ & $\begin{array}{l}\text { No (\%) } \\
\text { urgent }\end{array}$ & $\begin{array}{l}\text { No of } \\
\text { patients with } \\
\text { complaints }\end{array}$ & $\begin{array}{l}\text { No (\%) } \\
\text { urgent }\end{array}$ \\
\hline Impaired consciousness only & 97 & $27(28)$ & 22 & $5(23)$ & 3 & $1(33)$ & 60 & $28(47)$ \\
\hline Dyspnoea only & 16 & 2(13) & 1 & $1(100)$ & 5 & $1(20)$ & 16 & $12(75)$ \\
\hline Chest discomfort only & 37 & $13(35)$ & 0 & - & 11 & $7(64)$ & 36 & $10(28)$ \\
\hline Abdominal discomfort only & 7 & 0 & 1 & 0 & 5 & 0 & 11 & $3(27)$ \\
\hline Unknown complaint & 2 & 0 & 2 & $2(100)$ & 0 & - & 2 & \\
\hline Combination of complaints & 18 & $4(22)$ & 0 & - & 16 & 2(13) & 30 & $14(47)$ \\
\hline $\begin{array}{l}\text { Any combination which } \\
\text { included chest discomfort }\end{array}$ & 50 & $22(44)$ & 0 & - & 23 & $9(41)$ & 60 & $19(32)$ \\
\hline All complaints & 177 & $51(29)$ & 26 & $8(31)$ & 40 & $11(28)$ & 155 & $67(43)$ \\
\hline
\end{tabular}


Table 7 Characteristics of calls in relation to caller. Values are numbers (percentages) of calls unless stated otherwise

\begin{tabular}{lllccc}
\hline Characteristic & $\begin{array}{l}\text { Messenger } \\
(n=177)\end{array}$ & $\begin{array}{l}\text { Witness } \\
(n=26)\end{array}$ & $\begin{array}{l}\text { Patient } \\
(n=40)\end{array}$ & $\begin{array}{l}\text { Relative } \\
(n=155)\end{array}$ & $\begin{array}{l}\text { Total } \\
(n=398)\end{array}$ \\
\hline $\begin{array}{l}\text { Panic in caller's voice } \\
\begin{array}{l}\text { Caller leading the } \\
\text { conversation }\end{array}\end{array}$ & $18(10)$ & $4(15)$ & $7(18)$ & $41(26)$ & $72(18)$ \\
$\begin{array}{l}\text { Median duration } \\
\text { (range) (s) }\end{array}$ & $39(22)$ & $2(8)$ & $8(20)$ & $17(11)$ & $68(17)$ \\
\hline
\end{tabular}

Table 8 Prediction of non-urgent calls. Values are numbers of calls

\begin{tabular}{|c|c|c|c|c|c|c|}
\hline \multirow{3}{*}{$\begin{array}{l}\text { Urgency of } \\
\text { call according } \\
\text { to dispatcher }\end{array}$} & \multicolumn{6}{|c|}{ Urgency of call at follow up } \\
\hline & \multicolumn{3}{|c|}{ Placed by patient or relative } & \multicolumn{3}{|c|}{ Placed by messenger or witness } \\
\hline & Urgent & Non-urgent & Total & Urgent & Non-urgent & Total \\
\hline $\begin{array}{l}\text { Urgent } \\
\text { Non-urgent } \\
\text { Total }\end{array}$ & $\begin{array}{r}74 \\
3 \\
77\end{array}$ & $\begin{array}{r}92 \\
26 \\
118\end{array}$ & $\begin{array}{r}166 \\
29 \\
195\end{array}$ & $\begin{array}{r}58 \\
1 \\
59\end{array}$ & $\begin{array}{r}139 \\
5 \\
144\end{array}$ & $\begin{array}{r}197 \\
6 \\
203\end{array}$ \\
\hline
\end{tabular}

Table 7 shows characteristics of the call in relation to the caller. In most calls $(82 \%)$, the caller's voice was normal and conversational. Panic in the caller's voice was most often encountered in calls placed by relatives $(26 \%$ $(41 / 155) v 12 \%(29 / 243), \mathrm{p}<0.001)$. Only in a few cases $(17 \%)$ was the conversation led by the caller; messengers more often led the conversation than did relatives $(22 \% v 11 \%, \mathrm{p}<$ $0 \cdot 01$ ).

The median duration of all calls was 69 seconds, ranging from 15 to 562 seconds. Calls placed by the patient had the highest median duration (118 seconds), which was significantly higher than the duration of calls placed by witnesses (46 seconds $p<0.05$ ). No relation was found between any of the described characteristics and the urgency of the call.

\section{RECOGNITION OF NON-URGENT CONDITIONS}

The decision taken by dispatchers not to dispatch an emergency ambulance was compared with the true urgency in calls placed by either the patient or a relative (providers of ample information) and in calls placed by a messenger or a witness (providers of less information) table 8. Dispatchers were well able to recognise non-urgent calls from medically urgent calls. With a prevalence of nonurgency of $61 \%$ in calls placed by patients and relatives and $71 \%$ in calls placed by messengers and witnesses, dispatchers showed a correct predictability of non-urgency of $90 \%$ and $83 \%$. Of the calls considered to be medically urgent by dispatchers, however, $55 \%$ placed by patients and relatives turned out to be nonurgent, compared with $71 \%$ of calls placed by messengers and witnesses.

\section{Discussion}

The main objective of an emergency medical service is to offer emergency treatment and ambulance transportation to patients requiring immediate medical attention. As time is a critical factor in true emergencies, emergency telephone numbers ensure the availability of medical care at an early stage. The safest strategy for the dispatchers in achieving this goal is to send an ambulance in response to every incoming emergency call.

This strategy of "safety first" has many consequences. On the one hand, it ensures the fastest help possible for those who truly need it. On the other hand, it adds unnecessarily to costs for those who, in retrospect, are transported unnecessarily. These costs include not only the added burden on emergency rooms, doctors, nurses and diagnostic facilities but also the limited availability of ambulances and the psychological impact on the patient whose initial fear of a serious problem is subsequently confirmed by the response of the medical community. ${ }^{6}$

Rising financial constraints force a more selective approach to this safety first strategy, and dispatchers could be more efficient if they could perform adequate triage of emergency calls and dispatch an emergency ambulance only when one was required.

Little is known about the size of the problem. To our knowledge evaluation of the decisions made by dispatchers has not been published before-neither for possible unwarranted transportations nor for unjustifiedly withholding the emergency ambulance.

Our results are an audit of the current situation in two emergency medical services in The Netherlands. Except for the unique option in Enschede to have a general practitioner on call to assess a case the results may be seen as representative for dispatch centres manned by nurses who have no formal protocols. Implementation of protocols or decision algorithms may, however, alter the scene.

The most important finding was the high proportion of patients $(28 \%)$ with nonorganic disorders. The lack of definite diagnosis of any kind does not exclude the possibility that true disease was present at the moment of the call, such as bradycardia causing syncope or atypical angina pectoris subsiding before examination, but such a condition was clearly self-limiting. Non-organic disorders were seen in similar frequency in all groups of main complaints. Identification of these patients, based only on the chief complaint, seems therefore impossible.

$47 \%$ of all diagnoses were cardiac. This was partly because of the entry selection in the study, which was intended to identify in the first sentences of the call acute cardiac ischaemic syndromes, yet wide enough to cover a variety of non cardiac acute syndromes. The high proportion of cardiac disorders may reflect the awareness in the population of the potential consequences of chest discomfort following the educational efforts of institutions such as the Netherlands Heart Foundation.

Only $39 \%$ of all calls could be classified as urgent in retrospect and warranting emergency ambulance transportation. Only one subgroup (calls dealing with abdominal discomfort) could be identified as being less urgent than average. With respect to the 
person making the call or the character of the call (particularly panic in the voice), only relatives were good predictors of urgency.

In retrospect an ambulance would have been indicated in four of the 35 calls in which the dispatcher referred the patient to a general practitioner instead of sending an ambulance. Only when dispatchers are able to obtain medical information (calls placed by the patient or a relative) is there scope for not dispatching an ambulance. When calls are placed by minimally or uninformed callers the safetyfirst policy is adopted quickly.

The consequences of bypassing the general practitioner in conjunction with the "safety first" policy of the dispatchers clearly leads to a large number of patients being taken by ambulance as emergencies to hospital; this imposes a great burden on the emergency system. Several options of improvement should be considered. Changing the policy by restricting the availability of ambulances on general practitioner requests only or imposing a restrictive budget, must lead to fewer emergency transportations but inevitably at the expense of longer delays or more patients left at home, who could have benefited from emergency care.

The triage capabilities of general practitioners have rarely been studied; available information $^{7}$ and anecdotal experience suggest that many patients who are transported under the diagnosis of acute myocardial infarction on request of the general practitioner do not have an acute condition confirmed in hospital. In others the diagnosis was wrongly labelled as non-urgent, requiring no emergency treatment. Even when acute ischaemia is correctly diagnosed at home by a general practitioner, it adds many minutes to the institution of appropriate treatment. This applies not only to coronary thrombolysis, whose benefit is greatly related to the delay in treatment, ${ }^{8-9}$ but also to monitoring and defibrillation because the outcome of prehospital resuscitation is much better when defibrillation is immediate and basic life support is needed for only a short time or not at all.

The results from Enschede suggest that an emergency general practitioner service can be a substitute for emergency ambulance calls, but in $17 \%$ of cases leads to subsequent delayed transportation.

An alternative approach could be to improve triage by focusing the education of dispatchers on the identification of nonurgent cases. Well designed and appropriately evaluated decision algorithms might be helpful in the process, but such algorithms have not yet been developed and tested.

We thank the following people, without whose support this study never could have been successfully performed: $\mathrm{Mr}$ V Zocca for his programming skills; Mrs E Zwartelé-van Dongen for her administrative support; the staff of all the cooperatin hospitals and the general practitioners in Amsterdam and Enschede; the medical and nursing staff of the dispatch centres of Amsterdam and Enschede; Drs E Iwema Bakker and A E Zurel, Sisters P Wieringa and W ten Wolde; and above all, the dispatchers who were willing to perform the the dispatchers who were willing to perform the additiona 39-006 from The Netherlands Heart Foundation.

1 Fitzpatrick B, Watt GCM, Tunstall-Pedoe H. Potential impact of emergency intervention on sudden deaths from coronary heart diseases in Glasgow. Br Heart $\mathcal{F}$ 1992;67:250-4.

2 Rowley JM, Mounser P, Harrison EA, Skene AM, Hampton JR. Management of myocardial infarction: implications for current policy derived from the Nottingham heart attack register. Br Heart $f 1992 ; 67$ : 255-62.

3 Siemiatycki J, Campbell S. Non response bias and early versus all responders in mail and telephone surveys. $A m \mathcal{F}$ Epidemiol 1984;120:291-301.

4 Eisenberg MS, Carter WB, Hallstrom AP, et al. Identification of cardiac arrest by emergency dispatchers. $A m \mathcal{F}$ Emer Med 1986;4:299-301.

5 Miettinen OS. Theoretical epidemiology. Principles of occur rence research in medicine. New York: J Wiley, 1985 155-71.

6 Wilcox RG, Roland JM, Hampton JR. Prognosis of patients with 'chest pain? cause.' BMf 1981;282:431-3.

7 Does E van der, Lubsen J. Acute coronary events in general practice: the imminent myocardial infarction Rotterdam study. [thesis] den Haag: de Swart, 1978. 280pp.

8 Simoons $\mathrm{ML}$, vd Brand $\mathrm{M}$, de Zwaan C. Improved survival after early thrombolysis in acute myocardial infarction. Lancet 1985;ii:578-82.

9 Gruppo Italiano per lo Studio della Streptochinasi nell'Infarto miocardico (GISSI). Effectiveness of intravenous thrombolytic treatment in acute myocardia infarction. Lancet 1986;1:397-401. 